\title{
(1)
}

\begin{tabular}{|l||c|c|}
\hline \hline Received 24.05.2021 & & JOTS \\
$5 / 2$ \\
\hline \hline Accepted 10.06.2021 & Review & $2021: 424-433$ \\
\hline \hline Published 24.07.2021 & & \\
\hline
\end{tabular}

\section{Seçkin, K. Eski Türkçe Metinlerinden Örneklerle Mental Fiil Teorisi, Konya: Palet Yayınları, 2020, ss. 175, ISBN: 978-625-7675-01-7}

\author{
Yusuf GÖKKAPLAN * \\ Cappadocia University (Nevşehir/Turkey) \\ E-mail:yusuf.gokkaplan@kapadokya.edu.tr
}

Türk dili, yazılı kaynakları bin yılı aşkın bir geçmişe sahip olan, sözlü kaynakları ise ondan çok daha öncelere dayanan, yeryüzünde yaşayan kadim dillerin en önemlilerinden biridir. Gerek sözlü gerekse de yazılı kültür ile ortaya konulan eserlerin içerikleri oldukça zengindir ve etkili bir retoriğe sahiptir. $\mathrm{Bu}$ nedenledir ki Türk dili ile ortaya konulan eserlerin tümü zaman kavramına yenilmemiş ve klasik birer tür olarak tarihsel süreçte önemi tartışılamayacak bir değere sahip olmuştur. Orhun yazıtları ile başlayan bu süreç günümüze kadar yoğun ve derin içeriklerle gelmiş yerli veyahut yabancı birçok araştırmacının çalışmasına malzeme olmuştur.

Türk dili ile ortaya konulan eserlerin içerik ve konu bakımından çeşitlilik arz etmeleri, kadim Türk kültürünün harmonisi ile sağlanmıştır. Göçebe bir topluluk olan Türkler siyasi veya coğrafi sınırlara bağlı kalmadan geniş sahalarda varlıklarını sürdürmüşler, bu sahalarda karşılaştıkları kültürlerden etkilenerek kendi kültür ve birikimlerini de zenginleştirmişlerdir. Bu süreç içerisinde özellikle kültür, din, sosyal yapılarında ciddi ve köklü değişimler de yaşamışlardır. Yaşadıkları bu değişimlerin izleri ortaya koydukları yazılı eserlerden hareketle net bir biçimde görülmektedir. Özellikle farklı dinler ile kurdukları münasebetin neticesinde göçebe yaşam biçiminin terk edildiği, dünya

\footnotetext{
ORCID ID: 0000-0001-6515-4762.
} 


\section{0}

görüşlerinde ve algılarında farklılıklar yaşandığı açık bir şekilde görülmüştür. Bu tür köklü ve marjinal değişimler kültürel birikimlerinde, gündelik yaşantıya ait yansımalarında, kullanılan sözcük ve ifade biçimlerinde görülmektedir.

Türk dili üzerine yapılan çalışmalarda bu kaynakların daha çok gramer özellikleri ile ele alındığı söylenilebilir. Yapılan çalışmalara bakıldığında eserlerin dönemlere göre taşıdıkları ses özellikleri, sözcüklerin kökeni, ekler ve eklerin yapıları, cümle sistemleri gibi konuların yoğunlukla ele alındığı dikkat çekmektedir. Bir dil üzerine yapılan çalışmaların fonetik, morfolojik, sentaktik ve semantik olarak dört ana başlık altında ele alındığı varsayılırsa Türk dilinin tarihi devirlerini konu alan çalışmalarda ses bilgisi, sözcük ve cümle yapısı konularının bir hayli fazlaca yapıldığı görülecektir. Söz konusu dönemlere ait eserler üzerinde semantik çalışmaların ise son dönemlerde yapıldı̆̆ görülmektedir.

Türk dilinin zengin içeriğe sahip olması, bu dili oluşturan söz varlığının derin bir anlam evrenine sahip olmasını da beraberinde getirmiştir. Bu nedenledir ki Türk dilinde yer alan sözcüklerin gerçek ve mecaz kullanımları oldukça geniştir. Bunun yanında Türkçenin sondan eklemeli bir dil olması, sözcük köküne gelen eklerin de sözcüğe yeni anlamlar kazandırmasına olanak sağlamaktadır. Bu noktadan hareketle Türkçenin ifade gücünün de semantik bir bakış açısı ile ele alınması gerektiği söylenebilir. Özellikle de göçebe bir topluluğun sözcük dağarcığı içerisinde yer alan fiillerin bu bağlamda değerlendirilmesi Türk topluluklarının sadece fiil noktasında değil tefekkür noktasında da ne kadar ileri olduğunu gösterebilecek bir potansiyel arz etmektedir.

Bu bakış açısı ile son dönemlerde dikkat çeken çalışmaların başında mental fiil çalışmaları gelmektedir. Mental fiiller, Türk dilinin fikir ve tasavvur düşüncesinin dile yansıması olarak değerlendirilebilecek önemli bir konu olarak dikkat çekmektedir. Özellikle de fiillerin semantik yönünün sadece hareket merkezli değerlendirilmesi zihinsel veya duygusal bağlamda kullanılan fiillerin anlaşılmasını ve ayırt edilmesini güçleştiren bir unsur olarak değerlendirilebilir. $\mathrm{Bu}$ durum ise fiillerin sadece hareket ifadesi olarak değil de mental bir süreç içerisinde de kullanıldığının da ortaya konulmasını gerekli kılmaktadır. 
Son dönemlerde daha çok dilbilim çalışmaları ile dikkat çeken bu konunun daha önceleri psiko-bilişsel dilbilimin araştırma ve çalışma alanı olarak kullanıldığı görülmektedir. Söylenilen ile yapılanın, yapılan ile söylenilenin arasındaki ilişkinin daha çok semantik düzlemde incelendiği bu çalışmalara Türk dilinin tarihi devirleri üzerinde yapılan çalışmalarda da yer verilmeye başlanmıştır.

Türk dilinde yer alan mental fiil kavramının bir teori olarak değerlendirildiği güncel çalışmalardan biri de bu tanıtım vesilesi ile ele alınacak eserdir. Eser genel olarak Eski Türkçe dönemi eserlerinin söz varllğg temel alınarak hazırlanmıştır ve iki ana bölüm üzerine kurgulanmıştır. İlk bölümde fiil kavramı üzerinde durulmuş ve bu konu üzerinde yapılan çalışmalardan genel olarak bahsedilmiştir. Bu tutum, "Türk dilindeki mental fiil ne demek?" sorusunun cevabının verilmesini ve konu sınırlarının net bir tavırla çizilmesini sağlamıştır. Eserin ikinci bölümünde ise ilk bölümde yer alan mental fiil kavramlarının yapıcı eleştirilerine yer verilmiştir. Buradaki amaç, "Hangi fiil mental fiildir?" sorusunun cevabını arayarak örnekler ile ifade etmektir.

Eseri farklı kılan özelliklerden birisinin de mental fiil algısının geçerliliğinin ve güvenirliliğin tespit edilmesi gayreti olduğu söylenilebilir. Bu bağlamda bir Uygur Dönemi metni olan Edgü Ögli Tigin Anyıg Ögli Tigin adlı eser beş farklı araştırmacıya mental fiillerinin tespit edilmesi amacıyla verilmiştir. Söz konusu tespitler araştırmacılar tarafından kategorilere ayrılmış ve bu kategorilerdeki fiiller üzerine tartışılmış ve büyük oranda mutabakat sağlanmıştır. Bu süreç, Türk dili üzerinde yapılan çalışmalarda deneysellik ve ölçülebilirlik çalışmalarının uygulanması açısından önem arz etmektedir. Sosyolingüistik çalışmalarının metodolojisine benzeyen bu tutum, eserde tespit edilen mental fiil kullanımlarına objektif bir özellik katmıştır. Bunun yanı sıra fiillerde görülen ses değişimleri, ilgili dönemlerdeki kullanımlarına göre değerlendirilmiş, bir fiil farklı metinlerde birden farklı biçimde kullanılıyor ise ilgili fiiller aynı başlıkta değerlendirilmiştir. Ayrıca tespit edilen fiillerin edilgen durumları, etken durumlarına kıyasla "hareketin gerçekleşmesi" bakımından bir farklılık arz etmediği gerekçe gösterilerek (ve bu gerekçe örneklerle izah edilerek) aynı fiilin edilgen versiyonu yeni bir madde başı olarak verilmemiştir. Bunlara ek olarak fillerin anlamlandırılmasında bağlam merkezli bir tutum sergilenmiştir. Bağlam merkezli değerlendirme, sözcüklerin korpus ile anlamsal süreçleri 


\section{)(๑)}

arasındaki ilişkilerini yansıtması bakımından eseri özgün kılan başka bir taraf olmuştur.

Kitabın birinci bölümüne daha detaylı bakıldığında fiil tanımlarının, fiil tasniflerinin geniş̧̧e değerlendirildiği görülecektir. Buradaki değerlendirmeler literatürdeki kaynakların geniş bir biçimde değerlendirilmesiyle ifade edilmiştir. Bu tanım ve örneklem evreni sadece Türkiye Türkçesi ile sınırlandırılmamış aynı zamanda diğer Türk dillerinde yer alan fiil tanım ve tasniflerini içerecek biçimde verilmiştir. Ayrıca Türk topluluklarının düşünce dünyasının şekillenmesinde etkili olan kültür, din, sosyal yapı gibi konular da ele alınmış ve bu konuda açıklayıcı bilgiler verilmiştir. Yine bu bölümde mental fiil üzerine yapılan çalışmaların büyük çoğunluğu incelenmiş, bu çalışmalar ile ilgili örnekler verilerek konu zenginleștirilmiștir. Verilen bilgilerden ve yapıllan eleştirilerden hareketle mental fiil kavramının çerçevesinin çizildiği bu bölümde mental fiilin oluşabilmesi için o fiilin yönelimsel olması gerektiği belirtilmiştir. Kitapta bir fiilin mental fiil olabilmesinin şartı, o filin uzamsal olmaması ve yönelimsel olması ile ifade edilmiştir. Gündelik yaşantımızda da kullandığımız filllere de bu noktadan bakıldığında ortaya atılan teorinin geçerliliği görülmektedir. Nitekim uzamsal olarak gerçekleşen bir şeyin mental olarak kalması mümkün değildir.

Mental fiillerin ele alındığı birinci bölümde dikkate değer konulardan biri de mental fiil üzerine yapılan ilk çalışmaların insan psikolojisi ve dil edinimi çerçevesinde yapıldığıdır. Bilişsel dilbilim kategorisinde de değerlendirilebilecek bu fiiller söylem ile düşünce arasındaki ilişkinin incelenmesi ile ilgilidir. Bu alan, dilin bilişle nasıl etkileşime girdiğini, dilin düşüncelerimizi nasıl oluşturduğunu ve dilin zaman içinde toplumun ortak zihniyetindeki değişimine paralel olarak evrimini açıklar. Ağırlıklı olarak Eski Türkçe dönemi eserlerindeki fiillerin incelendiği Mental Fiil Teorisi adlı eserde, bu çalışma alanına değinilmesi de eseri farklı kılan özelliklerden biri olmuştur.

Birinci bölümün sonunda, mental fillerin zihinsel bir sürecin sonucunda oluştuğu ve mental fiillerin algı, duygu, idrak ve irade fiilleri olmak üzere dört başlıkta inceleneceği ifade edilmiştir. Genel olarak toparlayacak olursak, ilk bölüm mental fiil kavramının etraflıca incelendiği, mental fiillerin hangi başlıklar altında nasıl incelenmesi gerektiği ve bu bağlamda hangi korpusun kullanılacağını ifadesi ile sonlandırılmıştır. 


\section{四)}

Eserin ikinci bölümünde ise kitabın da adı olan "Mental Fiil Teorisi" ele alınmıştır. İkinci bölüm doğrudan mental fiil teorisi başlığı ile başlamaktadır. Bu kısımda fiillerin karşıladıkları anlamlardan hareketle tanımlamalarının yapıldığından ve bu tanımlamalardan hareketle bazı epistemolojik ölçütlerin ortaya konulmasından bahsedilmektedir.

Burada söz konusu edilen epistemolojik ölçütlerin dilbilimsel bir araç olarak gramer birliklerine uygulanması dikkate değer bir özelliktir. Epistemoloji (bilgi kuramı), bilginin doğrudan kuramsal bir şekilde ele alınması ile açıklanabilir (TDK Sözlük, 2021: 384). Söz konusu kuramsal bilgi, fiillerin fiziksel ve zihinsel olup olmadığının ayırt edilmesinde kullanılmaktadır. Eserde bir fiilin sadece epistemolojik özellikler göstermesinin mental olarak değerlendirilmesinde yetersiz kalabileceği ifade edilmiştir. Bir fiilde epistemolojik özelliklerin yanında yönelimsel özelliklerinin olması mental olarak adlandırılmasında önemli bir ölçüt olarak belirlenmiştir. Bu kıstaslara ilk bölümde söz konusu edilen uzamsal olmama durumu da eklenmiş ve mental fiillerin teorik çerçevesi çizilmiştir. Böylelikle eserin omurgasını oluşturan mental fiil kavramının bilimsel bir düzlemde ifadesi gerçekleştirilmiştir.

Dilbilimin toplumbilimle, ruhbilimle, müzikbilimle, psikoloji ve kültür bilimle olan ilişkisi disiplinler arası bir çalışma alanı olarak değerlendirilebilir. Yazarın, mental fiilleri değerlendirme ölçütleri dilbiliminin çalışma alanı olarak değerlendirildiğinde eserin disiplinler arası bir bakış açısı ile ele alındığı görülecektir. Yazar burada mental fiil kavramından yola çıkarak zihinsel, düşünsel, uzamsal ve yönelimsel unsurların sentezini gerek dil bilgisi çalışmaları ile gerekse de disiplinler arası bir yaklaşım güderek felsefe, dilbilim, kültür bilim ve psikoloji gibi alanların kuram ve bakış açılarıyla değerlendirmiş, konuyu bilimsel ve kuramsal bir düzlemde objektif bir bakış açısı ile değerlendirmeye çalışmıştır. Bu tavır esnasında gerek alandan gerekse de alan dışından birçok çalışma taranmış, önemli görüş ve fikirler bu kısımda zikredilmiş ve savunulan düşüncenin isnadı güçlendirilmiştir.

Burada söz konusu edilmesi gereken önemli bir nokta da mental fiilin oluşmasında girdi ve çıtı süreçleridir. Bir fiilin çeşitli uyaranlar vasıtası ile girdi olarak zihne girmesi ve uzamsal olmadan zihinde var olmasının süreci olarak ifade edilebilecek bu süreç mental fiilin oluşması için önemli bir aralık olarak 


\section{ग(৫)}

görülmektedir. Burada uzamsal olmamasına ek olarak yönelimsel olma koşulu da sürecin önemli bir paydaşıdır. Nihayetinde bu sürece dâhil olan ve süreci ifade edebilen fiillerin mental olarak adlandırılabileceği ifade edilmiştir. Bu kısımda önemli olan nokta mental filler için genel-geçer, nesnel ve objektif bir tanımın ortaya konulma çabasıdır.

Türk dilinde birçok alanda karşıllaştı̆̆ımız terminoloji ve tanım sorunu eserin hemen başlarında mental fiiller için açık bir şekilde ifade edilmiş, tanım ve terminolojiden doğabilecek karışılıkların önüne geçilmiştir.

İkinci bölümde mental fiillerin hangi başlıklar altında inceleneceği ve bu başlıkların kavramsal olarak neler ifade ettiklerinin açıklanması ele alınmıştır. Bu kısımda ilk olarak "algı kavramı" açıklanmış ve bu kavramın doğru anlaşılabilmesi için "algı" izah edilmeye çalışılmıştır. Burada kullanılan metodoloji bundan sonraki başlık ve bölümler için de kullanılmıştır. $\mathrm{Bu}$ bölümlerde esas alınan metodolojide öncelikle kavram tanımları, sonra bu kavram tanımlarına dâhil olan mental fiillerin tespiti ve açıklaması, sonrasında ise tespit edilen örneklerin bağlam merkezli olarak verilmesi şeklinde devam etmiştir.

Bu başlıklar altında ele alınan tanım ve kavramların değerlendirilmesinde de diğer bölümlerde olduğu gibi geniş literatür taraması yapılmış, mümkün olduğu kadar fazlaca kaynağa ulaşılmıştır. Yapılan tanımların ve açıklanmaya çalışılan kavramların daha önce yapılmış olanlardan farkı ve nasıl olması gerektiğine dair teklifler verilmiştir. Karşılaştırmalı referans olarak değerlendirebileceğimiz bu metodun kitapta genel bir tavır olarak değerlendirilmesi eseri farklı ve nesnel kılan bir özellik olarak değerlendirilebilir. Algı kavramı ve algı fiilleri başlığı altında açıklamalar yapıldıktan sonra çeşitli araştırmacıların algı fiilleri tasniflerinin tablo ve şekiller ile verilmesi de alg1 fiillerinin literatürdeki yerinin daha iyi anlaşılmasını sağlamıştır. Geniş ve karşılaştırmalı bir açıklamadan sonra Eski Türkçede tespit edilen algı fiilleri bağlam merkezli olarak verilmiştir. Bu kısımda verilen örneklerin sadece bağlam merkezli anlamları ve sözlük anlamları verilmemiş her bir fiil üzerinde detaylı açıklamalar yapilmış, yapılan açıklamalar daha önce yapılan çalışmalar ile desteklenmiştir. Algı fiilleri başlığının sonunda, tespit edilen algı fiilleri ve bu fiillerin literatürdeki karşılaştırmaları değerlendirmiş ve tespit edilen algı 


\section{J(৫)}

fiillerinin genel bir tablosu verilmiştir. Bu tabloda fiilin anlamı ve hangi metinlerde kullanıldığı bilgisi açık, anlaşııır bir biçimde verilmiştir.

İkinci alt başlık olan Duygu Kavramı ve Duygu Fiilleri başlıklarının oldukça detaylı bir biçimde ele alınması dikkate değerdir. Bu başlık altında verilen Eski Türkçedeki duygu fiillerinin bağlam merkezli olarak psikolojik ve bilişsel bakış açısıyla ele alınması, tespit edilen fiillerin detaylı olarak incelenmesi, daha önce yapılan tespitlere de bu çerçeveden bakılması literatürdeki duygu fiilleri konusuna farklı bir derinlik katmıştır. Burada gösterilen titiz ve dikkatli çalışmanın neticesi olarak Eski Türkçede 139 farklı duygu fiili tespit edilmiştir. İkinci bölümde yer alan, "İrade Kavramı ve İrade Fiilleri, İdrak Kavramı ve İdrak Fiilleri” başlıkları da aynı metodoloji ile değerlendirilmiştir. Bu bölümde irade fiillerinin nasıl değerlendirilmesi gerektiği hususuna dair öneriler sunulmuş ve teklifler verilmiştir. Yazar irade fiillerinin istişare, karar ve icra olmak üzere üç başlıkta incelenebileceği önerisini sunarak bu konudaki tespitlerini açıklamıştır. Algı ve duyum konularında "Ne söylendi?" ve "Ne anlandı?" ilişkisi, gönderici tarafından gönderilen kodların alıcılar tarafından doğru dekodlanması hususunu düşündürmüş ve bu konu üzerinden yapılacak çalışmalar için bir zemin hazırlamıştır.

İkinci bölüme genel olarak bakıldığında, bazı terim ve terminolojilerin sözlük anlamlarının verilmesinin ifadelerin ve teorilerin daha da anlaşlır olmasını sağladığı görülmüştür. Her bir mental fiil başlığının sonunda genel olarak bir tablo verilmesi okuyucular ve özellikle de araştırmacılar için büyük kolaylık sağlamaktadır. Bu fiillerin hangi kaynaklarda hangi anlamda yer aldığının tespit edilerek bir form hâlinde sunulması oldukça işlevsel bir özellik olarak dikkat çekmektedir. Tespitlerin bu şekilde verilmesi, istatistiki verilerin hesaplanması için büyük kolaylık sağlayacaktır.

\section{Sonuç}

Sonuç olarak, Mental Fiil Teorisi adlı bu çalışma, mental fiillerin derlenerek tespit edildiği bir eser olmaktan ziyade mental fiillerin nasıl inceleneceğine dair bir yöntem teklifi sunmaktadır. Yazara göre bir fiilin mental fiil olarak değerlendirilebilmesi için "uzamsal olmaması ve yönelimsel olması" gerekmektedir. Mental fiillerin değerlendirilmesinde bu iki ölçüt muhakkak 


\section{J(e)}

bulunmalıdır. Eserde bu sürece dâhil olan mental fillerin ifade edilmesinde kullanılan şema aşağıdaki gibidir.

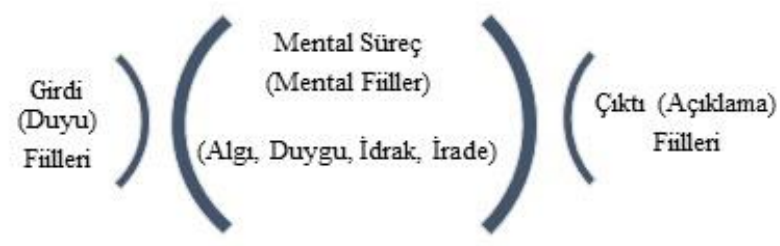

Mental süreç izah edildikten sonra, mental süreçlerin işlemesi üzerinde durulmuştur. Mental süreçler birbirini etkileyen, değiş̧tirebilen bir niteliktedir ve çizgisel bir yapıda bulunmazlar bunun aksine döngüsel bir yapıya sahiptirler. Bu döngüsel yapıya ilişkin süreç aşağıdaki şekil ile izah edilmiştir.

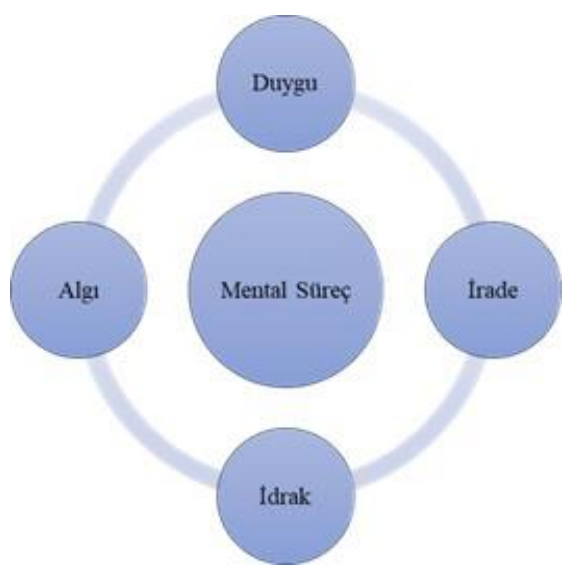

Bu süreç ve döngü çerçevesinde ele alınan fiillerin mental olup olmadığının tespiti yapılmıştır. Yazar bu çalı̧̧mada ortaya koymuş olduğu teoriye bağlı olarak 292 mental fiil tespit etmiştir. Sonuç kısmında tespit edilen mental fiillere ait mental süreçler ve örnekler tablosu verilmiştir. Aşağıda örneği verilen bu tabloda mental sürecin bağlam merkezli olarak nasıl değerlendirildiği görülmektedir.

\begin{tabular}{|c|c|c|}
\hline $\begin{array}{l}\text { MENTAL } \\
\text { SÜREÇ }\end{array}$ & Fİil & BAĞLAM \\
\hline ALGI & $\begin{array}{l}\text { işid-/eşid- } \\
\text { (dinlemek) }\end{array}$ & $\begin{array}{c}\text { antada ınaru kün künüye } \\
\text { bodisvtaġ körgeli kelir titrü } \\
\text { terin nom işidür... (küsüş̧in) } \\
\text { iyin edgü avrış kılur (MS } \\
\text { 38/45). } \\
\text { “O andan itibaren her gün } \\
\text { Bodhisattva'yı görmeye gelir, } \\
\text { derin vaazını dinler... } \\
\text { (Arzusuna) göre iyi hareket } \\
\text { eder.” }\end{array}$ \\
\hline
\end{tabular}


四)

\begin{tabular}{|c|c|c|}
\hline DUYGU & $\begin{array}{c}\text { buş- } \\
\text { (hiddetlenmek) }\end{array}$ & $\begin{array}{c}\text { ökünçlük bolur tutşı övke işi / } \\
\text { yazuḳlug bolur işte buşsa kişi } \\
\text { (KB 324). } \\
\text { “Öfkeyle kalkan pişmanlıkla } \\
\text { oturur, kişi hiddetlenince } \\
\text { işinde yanılır.” }\end{array}$ \\
\hline İDRAK & $\begin{array}{c}\text { bögün- } \\
\text { (düşünmek) }\end{array}$ & $\begin{array}{l}\text { köyülin köküzin yakçırțıp ol } \\
\text { iki eçilerin köyülgerip neçökin } \\
\text { erser tuysar oyarsar ötrü } \\
\text { ürküp belinlenip tıdıg ada kılıp } \\
\text { küsemiş küsüşümin } \\
\text { kandurmagay tep bögünüp } \\
\text { ötrü iki eçilerine azkıya öyre } \\
\text { yorıyu turzunlar men una basa } \\
\text { tetdim tep öțünüp... (Açp 246). } \\
\text { ‘kalbini ferahlatıp o iki } \\
\text { ağabeyini aklından geçirerek: } \\
\text { 'Her nasıl (olup da) } \\
\text { hissederlerse sonra korkup } \\
\text { engel olup isteğime karş1 } \\
\text { gelmesin(ler).' diye düşünüp } \\
\text { sonra iki ağabeyine '(Siz) } \\
\text { azıcık } \\
\text { ileri yürüyüverin, ben hemen } \\
\text { yetişirim.' diye rica edip...” }\end{array}$ \\
\hline İRADE & $\begin{array}{c}\text { kes- } \\
\text { (karar vermek) }\end{array}$ & $\begin{array}{l}\text { havaḳa basıkma ukuş birle kes } \\
\text { / et öz arzu bulsa bilig birle } \\
\text { bas (KB 3346). } \\
\text { "Hevesin etkisinde kalma, akıl } \\
\text { ile karar ver; ten baş kaldırırsa } \\
\text { bilgiyle hâkim ol." }\end{array}$ \\
\hline
\end{tabular}

Bu tablodan sonra tespit edilen fiillerin hangi mental kategoride yer aldığını gösteren ve kullanıldığı metinleri içeren genel bir tablo verilmiştir. Bu tablonun da bir kısmı aşağıda örnek olarak verilmiştir.

\begin{tabular}{|l||l||l||l||}
\hline Mental Fiil & Anlamı & Türü & Kullanıldığı Metin \\
\hline \hline kör- (I) & Görmek & Alg1 Fiili & Açp, AH, BK, Çaş, Dan, \\
& & Edg, Irk, KB, Kör, KP, \\
& & KT, MS, Muk, Myb, \\
& & & Suc, Şin, Üçi \\
\hline \hline kulak tut- & Kulak vermek, & Algı Fiili & KB \\
& dinlemek & & \\
\hline
\end{tabular}




\section{Ј(৫)}

\begin{tabular}{|c|c|c|c|}
\hline açıg kel- & $\begin{array}{l}\text { Acımak, keder gelmek, } \\
\text { üzülmek }\end{array}$ & Duygu Fiili & Açp \\
\hline ökün- & Pişman olmak & Duygu Fiili & $\begin{array}{l}\text { AH, BK, Hua, Kör,KT, } \\
\text { MS }\end{array}$ \\
\hline uḳ- (II) & $\begin{array}{l}\text { Anlamak, bilmek, } \\
\text { tasavvur etmek }\end{array}$ & İdrak Fiili & $\begin{array}{l}\text { Açp, AH, Edg, KB, MS, } \\
\text { Üçi }\end{array}$ \\
\hline sakın- & Düşünmek & İdrak Fiili & $\begin{array}{l}\text { Açp, AH, BK, Caş, Dan, } \\
\text { Edg, Hua, Irk, KB, Kör, } \\
\text { KP, KT, MS, Muk, Ong, } \\
\text { Şin, Tar, TY, Üçi }\end{array}$ \\
\hline tapla- & $\begin{array}{l}\text { Uygun görmek, } \\
\text { onaylamak }\end{array}$ & İrade fiili & $\begin{array}{l}\text { Açb, Edg, KB, Kör, MS, } \\
\text { Myb, Üçi }\end{array}$ \\
\hline unama- & $\begin{array}{l}\text { Doğru bulmamak, } \\
\text { uygun görmemek, } \\
\text { onaylamamak }\end{array}$ & İrade fiili & $\begin{array}{l}\text { Dan, Edg, Irk, KB, KP, } \\
\text { MS, TY }\end{array}$ \\
\hline
\end{tabular}

Yazar eserde, geniş literatür taraması ve çeşitli örneklem evreni ile genel olarak mental fiil kavramının çerçevesini çizmiş, bu düşüncesini de bir süreç olarak değerlendirmiş ve yukarıda verilen tablolar ile de bu süreci izah etmeye çalışmıştır. Yazar, bu zamana kadar yapılan çalışmaları, günümüzde yapılıyor olan çalışmaları değerlendirmiş ve nihayetinde bu alanda yapılacak olan çalışmalara için bir yöntem teklifinde bulunmuştur. 